\title{
Subgroups of lifestyle patterns among hypertension patients: a latent-class analysis
}

\author{
Jalileh Ghanbari ${ }^{1}$, Asghar Mohammadpoorasl ${ }^{2,3}$, Leila Jahangiry ${ }^{1,3^{*}}$ (D), Mahdieh Abbasalizad Farhangi ${ }^{4}$, \\ Jamileh Amirzadeh ${ }^{5}$ and Koen Ponnet ${ }^{6}$
}

\begin{abstract}
Background: Hypertension remains one of the most important preventable risk factors for diseases and death. Identifying clustered patterns of modifiable lifestyle risk factors for hypertension and demographics factors related to these clustered patterns allows for targeting health prevention interventions. Therefore, this study aims to identify latent classes of hypertensive patients' lifestyle risk factors based on the clustering of four modifiable lifestyle risk factors: eating, physical activity patterns, smoking habits, and blood pressure control.

Methods: $A$ total of 750 patients ( $M_{\text {age }}=65.38$ years, $S D_{\text {age }}=9.2$ years) with diagnosed hypertension in urban and rural primary health care centers in Takab (Iran) were recruited randomly from August 2016 to February 2017. Latent class analysis was performed by using proc. LCA in SAS 9.2.

Results: Three classes of lifestyle patterns were identified. About $14.4 \%$ of hypertensive patients were categorized in a low-risk class (I), 54.6\% in an intermediate-risk class (II), and 31\% in a high-risk class (III) of lifestyle. A one-year increase in age significantly increases the risk of membership in classes II and III. Similarly, being widowed or divorced increases the risk of membership in classes II and III. Also, having a higher education level decreases the risk of membership in classes II and III.

Conclusions: This study contributes to the literature on lifestyle behaviors among older adults and provides evidence that there are considerable differences in lifestyle behaviors between subgroups of older adult patients. The three profiles of hypertensive patients' conditions suggest that because behaviors often occur simultaneously within an individual level, a latent-class approach helps cluster co-occurrence risk behaviors and focuses on interventions targeted to several healthy behaviors among high-risk patients.
\end{abstract}

Keywords: Latent class analysis, Lifestyle pattern, Hypertension, Ageing

\section{Background}

Hypertension remains one of the most important preventable risk factors for diseases and death. The prevalence of hypertension is increasing with age, and by the age of 60-69 years, more than half of a population has high blood pressure [1,2]. The World Health Organization estimates that about one billion people suffer from hypertension worldwide and accounts for

\footnotetext{
* Correspondence: Jahangiry@razi.tums.ac.ir

${ }^{1}$ Health Education and Health Promotion Department, School of Public Health, Tabriz University of Medical Sciences, Tabriz, Iran

${ }^{3}$ Tabriz Health Services Management Research Center, Tabriz University of Medical Sciences, Tabriz, Iran

Full list of author information is available at the end of the article
}

approximately 7.5 million deaths per year [3]. It is estimated that by $2025,60 \%$ of adults will suffer from hypertension [4]. This represents a continuing trend in which the prevalence and absolute number of hypertensive patients has increased at a steep rate $[3,5]$. Evidence indicates that hypertensive patients are at an increased risk of several chronic diseases, such as coronary artery diseases, stroke, and cardiovascular mortality [6], as well as some cancers [7]. Increased cardiovascular mortality in developing countries is largely due to modifiable risk factors, such as salt intake, smoking, physical inactivity, obesity, unhealthy eating habits, and in some cases,

(c) The Author(s). 2018 Open Access This article is distributed under the terms of the Creative Commons Attribution 4.0 International License (http://creativecommons.org/licenses/by/4.0/), which permits unrestricted use, distribution, and reproduction in any medium, provided you give appropriate credit to the original author(s) and the source, provide a link to the Creative Commons license, and indicate if changes were made. The Creative Commons Public Domain Dedication waiver (http://creativecommons.org/publicdomain/zero/1.0/) applies to the data made available in this article, unless otherwise stated. 
non-modifiable risk factors, such as age, gender, and heredity [8].

A systematic review of studies on hypertension among Iranian adults revealed that the prevalence of hypertension is 60\% [9]. Recent evidence of the Framingham Heart Study indicates that systolic blood pressure is the most prevalent type of hypertension in patients aged 50 or above, so that by increasing the age, SBP increases by $10 \%$ per decade [10]. The pattern of diastolic blood pressure, however, differs with ageing, i.e. it increases until people are in the fifth decade, and slowly declines when people are over 60 years old [11].

Effective lifestyle modification programs and affordable strategies to control high blood pressure would benefit the at-risk populations [12]. The main causes of mortality in adults, especially in older adults, are that $53 \%$ of deaths are linked to unhealthy lifestyles and behaviors [13], like physical inactivity, tobacco smoking, poor diet, and excessive alcohol consumption. Most often, these unhealthy behaviors occur simultaneously or cluster within individuals $[14,15]$. To date, the majority of studies focus only on changing a single unhealthy behavior. However, interventions that target these unhealthy behaviors simultaneously are necessary [16]. Traditional cluster and factor analyses are designed for continuous variables, but a latent-class analysis (LCA) is suitable for discrete and dichotomous variables. Hence, some studies report that an LCA seems to be logical and is a more informative approach for describing health behaviors $[17,18]$.

An LCA is a commonly used empirical approach to identifying subpopulations by shared item response patterns. It is also a commonly used data reduction tool for analyzing multivariate categorical data [18]. A finite number of exclusive classes of individuals categorized as latent variables is assumed to compose this population [19]. An LCA can be used to identify lifestyle indicators as being healthy or less healthy and can help inform preventive health efforts to modify disease outcomes. Only a few studies have applied an LCA to help investigate lifestyle risk factor clustering $[17,19,20]$. A recent study used an LCA approach to predict healthy lifestyle patterns among retirement-aged older adults [17]. The authors identified two classes of lifestyle patterns: healthy (53\% men and $72 \%$ women) and less healthy lifestyles. They found there are meaningful gender differences in lifestyle behaviors among older adults.

Identifying the clustered patterns of modifiable lifestyle risk factors for hypertension and demographics factors related to clusters of unhealthy lifestyle factors allows targeting health prevention interventions. It is important, particularly among older hypertensive patients with respect to their individual barriers, to manage high blood pressure. Examining lifestyle risk factor clustering through an LCA for hypertensive patients may be relevant for guiding health prevention programs toward patients at a community level.

Therefore, the current study's aim is to identify latent classes of hypertensive patients' lifestyle risk factors based on the clustering of four modifiable lifestyle risk factors: eating patterns, physical activity patterns, smoking habits, and blood pressure control. We hypothesized that distinctive classes of major lifestyle patterns will be identified and that socio-demographic covariates, such as gender, would significantly predict the identified classes. Identifying the classes may indicate and inform who may be at risk of unhealthy lifestyle patterns.

\section{Methods \\ Design and participants}

This cross-sectional study was conducted in Takab, a county with an estimated population of 81,000 people and that is located in the West Azerbaijan province of Iran. A total of 750 patients with diagnosed hypertension in Takab's urban and rural primary health care centers were randomly recruited from August 2016 to February 2017. The inclusion criteria were 1) having diagnosed hypertension in the previous 6 months, 2) being aged 50 years and older, 3) living in Takab, and 4) having household health records in health care centers. Exclusion criteria were 1) having diabetes, 2) having cognitive disorders, and 3) having no interest in participating in the study.

Hypertensive patients aged 50 years and older from Takab's urban and rural regions were invited to participate in the study. During an Iranian diseases prevention program, all women and men were screened in Iranian Women Health Services (SABA; Persian name of program) and Iranian Men Health services (SAMA, Persian name of program) respectively. As such, all patients' health records were available in the health care centers. Patients with diagnosed hypertension were randomly selected and contacted by telephone. During the phone interview, eligible interested patients were asked to refer to health care centers for clinical assessment by trained health care researchers. In total, 750 patients completed the clinical assessment from the 900 invited patients (a response rate of $83.3 \%$ ).

\section{Latent-class indicators}

In this analysis, the underlying latent variable is healthy lifestyle patterns. Four indicators covering dietary patterns, physical activity, tobacco use, and high blood pressure control were selected. The indicators were chosen to ensure conditional independence of variables within each latent class [21]. Binary indicators (healthy versus unhealthy behavior) were created based on existing 
recommendations, as described below. The four binary indicators resulted in 24 possible response patterns.

\section{Dietary patterns}

Dietary intake was measured using a 147-item food frequency questionnaire (FFQ) [22] originally developed for the Tehran Lipid and Glucose Study (TLGS, Research Institute for Endocrine Sciences in Iran). The FFQ is a Willett-format questionnaire that has been adapted to the Iranian context and that includes questions about average consumption and frequency of 147 food items during the past year.

The Dietary Approaches to Stop Hypertension (DASH) adherence score was calculated based on dietary information from the FFQ questionnaire. This was a composite score, composing of subscores from seven food and nutrient components (grains and legumes, fruits and vegetables, nuts and seeds, dairy, meat, fats, and sodium). A score of 0 to 1 was given to each component based on intake compared to the intake recommendation, yielding a maximum total score of seven. We considered having six or more DASH diet elements indicated a healthy DASH diet, having 4-5 DASH diet elements was an intermediate DASH diet, and having? 3 DASH diet element was a poor DASH diet [23].

\section{Physical activity}

Walking, sitting, and engaging in moderate- and vigorous-intensity physical activities during the 7 days prior to the interview were measured using the International Physical Activity Questionnaire (IPAQ-short form), a well-validated questionnaire in Iran [24]. The total physical activity score was calculated by summation of the duration (in minutes) and frequency (days) of walking and moderate-intensity and vigorousintensity activities. In the present analyses, we used the metabolic equivalent (MET) (kcal/kg-hour) to measure an activity's intensity and energy expenditure in kilocalories. The metabolic equivalent score of an activity done by a participant was calculated as the product of the activity's MET and duration. A participant's total metabolic equivalent score (METS) was calculated by summing the products across all activities. Total physical activity (PA) was classified based on METS into two subgroups: METS <600 and METS? 600 [25].

\section{Smoking}

One question about smoking was included in the sociodemographic characteristics' section, and a binary variable for smoking was created (never smoked versus current and former smokers).

\section{Hypertension control}

According to the European Society of Hypertension and the European Society of Cardiology, a target of < 140/ $90 \mathrm{mmHg}$ for hypertensive patients is recommended [16].

\section{Anthropometric measurements}

Blood pressure was measured with a mercury sphygmomanometer twice in the same arm after the individual seated at rest for 10-15 min [1]. The individuals' weights-while the individuals were dressed in light clothing and without shoes-were measured using a calibrated scale (Seca, Hamburg, Germany model $8,811,021,658)$ to the nearest $0.1 \mathrm{~kg}$. Height was measured without shoes using a stadiometer (Seca, Hamburg, Germany) to the nearest $0.1 \mathrm{~cm}$ [26]. The body mass index (BMI) was calculated by dividing one's individual's weight in kilograms by the square of one's height in meters [27]. Waist circumference was measured to the nearest $0.1 \mathrm{~cm}$ with a measuring tape spanning the midpoint between the last rib and the iliac crest, with the subjects standing and breathing normally. Hip circumference was measured at the maximum level over light clothing using a nonstretchable tape measure, without any pressure against the body's surface. Measurements were recorded to the nearest $0.1 \mathrm{~cm} \mathrm{[28].}$

\section{Statistical analyses}

An LCA is a latent categorical variable model, and it classifies homogeneous individuals. An LCA model was performed using 4 indicator variables: physical activity) 2 response categories), dietary patterns (3 response categories), hypertension control (2 response categories), and smoking status (2 response categories) [29].

The descriptive continuous variables were analyzed using a one-way analysis-of-variances, and categorical variables were analyzed using a Chi-square test. The LCA analyses were conducted by using a proc. LCA in SAS 9.2 software. The LCA outcomes include the number of latent classes, the probability of each indicator in each class, and the classification of individuals based on their most likely latent-class membership. Due to various iterations for the number of the latent variable's identified classes, and by comparing the observed response patterns' frequencies with the expected response patterns, the LCA determines the best model and calculates a statistic similar to $\chi^{2}$, called G2. Based on the G2 statistic, Akaike information criterion (AIC) and Bayesian information criterion (BIC) can be calculated for model selection. For all information criteria, a smaller value represents a more optimal balance of model fit and parsimony; thus, a model with the minimum AIC or BIC might be selected [30-32]. For performing an LCA, four dichotomous observable variables (i.e., indicators) were 
used for assessing lifestyle behaviors as latent variables. After finalizing the model, an individual's age, marital status, and educational level were examined as covariates.

\section{Results}

The participants' descriptive characteristics are presented in Table 1 . The mean age of the hypertensive patients was 65.3 years $(S D=9.2)$. Women were significantly younger than men (at 63.3 years $[S D=9.2]$ and 68 years [ $S D=9.7]$, respectively). The majority of participants were female (56.1\%), illiterate (73.1\%), and married (77.2\%). Women were significantly less educated than men. The mean BMI was $26.8 \mathrm{~kg} / \mathrm{m}^{2}(S D=9.2)$. Women had a significantly greater BMI than men $\left(27.5 \mathrm{~kg} / \mathrm{m}^{2}\right.$ and $25.8 \mathrm{~kg} / \mathrm{m}^{2}$, respectively).

According to the task force for the arterial hypertension management of the European Society of Hypertension [15], about $43 \%$ of the participants had controlled hypertension. Based on the physical activity guideline, only $36.3 \%$ of the patients reached $P A$ ? 600 MET minutes/week; however, men had significantly higher PA levels than women. Also, only $8 \%$ of patients had the optimal adherence to DASH diet intake (having? 6 DASH elements).

\section{Latent-class findings}

The model-fit indices are shown in Table 2. Based on the four dichotomous indicators, there were 24 possible response patterns. We attempted to fit the LCA models with classes ranging from 1 to 5 . For each LCA model, the G2, AIC, and BIC were computed (Table 3). According to the model's indices and the model's results, we

Table 1 Descriptive characteristics of patients with hypertension

\begin{tabular}{|c|c|c|c|c|}
\hline & $\begin{array}{l}\text { Men } \\
(n=329) \\
\mathrm{N}(\%) / \text { mean }[\mathrm{SD}]\end{array}$ & $\begin{array}{l}\text { Women } \\
(n=421) \\
\mathrm{N}(\%) / \text { mean [SD] }\end{array}$ & $\begin{array}{l}\text { Total } \\
(n=750) \\
\mathrm{N}(\%) / \text { mean }[\mathrm{SD}]\end{array}$ & $p$-value \\
\hline Age in years & $68[9.7]$ & $63.3[9.2]$ & $65.38[9.2]$ & $<.0001$ \\
\hline Education & & & & $<.0001$ \\
\hline Illiterate & 195 (35.6\%) & $353(64.4 \%)$ & $548(73 \%)$ & \\
\hline Elementary & $122(37.08 \%)$ & $65(15.43 \%)$ & 187 (24.9\%) & \\
\hline $\begin{array}{l}\text { High school } \\
\text { and university }\end{array}$ & $7(2.12 \%)$ & $2(0.47 \%)$ & $9(1.2 \%)$ & \\
\hline Marital status & & & & .597 \\
\hline Married & 257 (44.4\%) & $322(75.05 \%)$ & $579(77.2 \%)$ & \\
\hline Single & $72(21.88 \%)$ & 99 (23.51\%) & $171(22.8 \%)$ & \\
\hline Body mass index & $25.8[3.8]$ & 27.5 [4.95] & $26.8[4.6]$ & $<.0001$ \\
\hline Systolic BP & $137.3[15.2]$ & 137.8 [17.6] & $137.6[16.6]$ & .680 \\
\hline Diastolic BP & $85.2[9.8]$ & 85.8 [11.3] & 85.5 [10.6] & .438 \\
\hline WC & $94.2[10.95]$ & 95.2 [13.7] & $94.8[12.6]$ & .285 \\
\hline
\end{tabular}

BP Blood pressure WC Waist circumference
Table 2 Comparison of LCA models with different latent classes based on model selection statistics

\begin{tabular}{llllllll}
\hline No. LCA & $\begin{array}{l}\text { No. parameters } \\
\text { estimated }\end{array}$ & Loglikelihood & $\mathrm{G}^{2}$ & $\mathrm{df}$ & $\mathrm{AIC}$ & $\mathrm{BIC}$ & $P$-value \\
\hline 1 & 5 & -1709.6 & 22.65 & 18 & 32.65 & 55.75 & .232 \\
2 & 11 & -1783.4 & 8.20 & 12 & 30.20 & 81.02 & .769 \\
3 & 17 & -1781.7 & 4.89 & 6 & 38.89 & 117.43 & .557 \\
4 & 23 & -1780.2 & 1.88 & 0 & 47.88 & 154.14 & - \\
\hline
\end{tabular}

Df degrees of freedom, AIC Akaike information criterion, BIC Bayesian information criterion

concluded that a three latent-class model was appropriate for the patients. The results of the three LCA model showed that differences between the expected and observed response pattern frequency were not statistically significant $(G 2=4.89, d f=6, p=.557)$.

Latent class membership and response probabilities for each indicator and covariates are summarized in Table 4. The probability of membership in each latent class is shown in the first row of Table 4. About $14.4 \%$ of hypertensive patients were categorized in the low-risk class (I), $54.6 \%$ in the intermediate-risk class (II), and $31.0 \%$ in the high-risk class (III) lifestyles. These probabilities form the basis for interpreting and labeling the latent classes.

The conditional probabilities of a "Yes" response to each risk behavior for lifestyle are listed in Table 4. The probability of a "No" response can be calculated by subtracting the item response probabilities from 1. Larger conditional probabilities are in bold to highlight the overall pattern. Latent class III was characterized by a high probability of responding "Yes" to nearly all of the risk-taking behaviors. Individuals in this latent class were likely to report that they had engaged in the study's listed risk-taking behaviors, including uncontrolled blood pressure (BP), inactivity, and adherence to? 3 DASH diet elements. In contrast, those in latent class I were likely to report not having smoked, maintaining a controlled BP, being inactive, and using more than six DASH diet elements.

The odds ratio indices of membership in each classcompared to the first class-and associated with the independent variables are also listed in Table 4. Membership in classes II and III increases with a one-year increase in age. Membership in classes II and III are also increased by being widowed or divorced. Membership in classes II and III are, however, decreased with a higher education.

\section{Discussion}

This study provides new evidence about the lifestyle patterns of patients with hypertension and identified subgroups of older adults with respect to their patterns of 
Table 3 Prevalence of each lifestyle behavior indicators used in the latent class analysis among patient with hypertension

\begin{tabular}{llll}
\hline Items & $\begin{array}{l}\text { Men } \\
(n=329) \\
n \text { yes (\%) }\end{array}$ & $\begin{array}{l}\text { Women } \\
(n=421) \\
n \text { yes (\%) }\end{array}$ & $\begin{array}{l}\text { Total } \\
(n=750) \\
n \text { yes (\%) }\end{array}$ \\
\hline Smoking & $108(32.8 \%)$ & $22(5.22 \%)$ & $130(17.3 \%)$ \\
Uncontrolled hypertension & $241(73.3 \%)$ & $186(44.2 \%)$ & $427(56.9 \%)$ \\
PA $<600$ MET-minutes/week & $191(58.1 \%)$ & $287(68.2 \%)$ & $478(63.7 \%)$ \\
Dash based diet & & & $198(26.4 \%)$ \\
Having $\leq 3$ dash elements (I) & $80(24.3 \%)$ & $118(28.02 \%)$ & $490(65.3 \%)$ \\
Having 4-5 dash elements (II) & $226(68.7 \%)$ & $264(62.7 \%)$ & $62(8.3 \%)$ \\
\hline
\end{tabular}

PA Physical activity, MET metabolic equivalent score

eating, smoking, maintaining physical activity, and ensuring hypertension control. The findings suggest a divergence in risk behaviors within hypertensive patients.

Four primary results are evident from this research. First, we identified three distinct profiles of hypertensive patients' lifestyle conditions, including a low-risk lifestyle (14.4\%), an intermediate-risk lifestyle (54.6\%),

Table 4 The three latent classes model of lifestyle behaviors and its covariates among patients with hypertension

\begin{tabular}{|c|c|c|c|}
\hline & $\begin{array}{l}\text { Low risk lifestyle - } \\
\text { Class I }\end{array}$ & $\begin{array}{l}\text { Intermediate risk } \\
\text { lifestyle - Class II }\end{array}$ & $\begin{array}{l}\text { High risk } \\
\text { lifestyle - } \\
\text { Class III }\end{array}$ \\
\hline Latent class prevalence & 0.144 & 0.546 & 0.310 \\
\hline \multicolumn{4}{|l|}{ Items } \\
\hline \multicolumn{4}{|l|}{ Smoking } \\
\hline No & 1.000 & 0.781 & 0.827 \\
\hline Yes & 0.000 & 0.219 & 0.173 \\
\hline \multicolumn{4}{|c|}{ Hypertension un-controlled } \\
\hline No & 1.000 & 0.347 & 0.313 \\
\hline Yes & 0.000 & 0.653 & 0.687 \\
\hline \multicolumn{4}{|l|}{ Physical inactivity } \\
\hline No & 0.408 & 0.367 & 0.334 \\
\hline Yes & 0.592 & 0.633 & 0.666 \\
\hline \multicolumn{4}{|l|}{ Nutrition status } \\
\hline $\begin{array}{l}\text { Having } \geq 6 \text { dash } \\
\text { elements (III) }\end{array}$ & 0.046 & 0.000 & 0.245 \\
\hline $\begin{array}{l}\text { Having } 4-5 \text { dash } \\
\text { elements (II) }\end{array}$ & 0.735 & 1.000 & 0.005 \\
\hline $\begin{array}{l}\text { Having } \leq 3 \text { dash } \\
\text { elements (I) }\end{array}$ & 0.219 & 0.000 & 0.750 \\
\hline Covariates (odds ratio) & & OR & OR \\
\hline Age (p 0.033) & Ref & 1.12 & 1.12 \\
\hline $\begin{array}{l}\text { Marital status (single) } \\
(p .089)\end{array}$ & Ref & 7.23 & 5.18 \\
\hline Education ( $p$ 0.009) & Ref & 7.14 & 0.77 \\
\hline
\end{tabular}

and a high-risk lifestyle (31\%). Second, class III was distinguished as high-risk class for lifestyle of hypertensive patients. Overall, hypertensive patients in class I are people with controlled BP (100\%) and who do not smoke cigarettes (100\%), who are not inactive (41\%), and who use 4-5 DASH diet elements (73\%). Third, hypertensive patients in class II are people with un-controlled BP (65\%) and who smoke cigarettes (22\%), are inactive (63\%), and use 4-5 DASH diet elements $(100 \%)$. Fourth, hypertensive patients in class III are people with un-controlled BP (68.7\%) and who smoke cigarettes (17\%), are inactive (66\%), and use fewer than three DASH diet elements (75\%).

The three profiles of hypertensive patients' conditions for lifestyle and behavioral risk factors suggest the need to treat common patterns of patients with hypertension simultaneously, thereby improving efficiency and cost-effective interventions. In two classes, most of the patients tended to have un-controlled hypertension and did not adhere to their medicines. Targeting high BP delivery services and more frequent and opportunistic BP testing are needed by the health care workforce, including primary care physicians, pharmacists, nurses, and other allied health professionals, as well as in primary health care settings [33]. Also, our results suggest a recommendation that regular screening and surveillance programs should be tailored and developed for older adult hypertensive patients.

It seems that for the control of hypertension among older adult patients, the fragmentation of health care for patients according to their lifestyle classifications appears to be an important contributor. To bring hypertension under control, simultaneous efforts focused on educating patients and providers about hypertension [34], developing efficacious primary and secondary prevention, and implementing lifestyle change interventions in people at elevated risk can help reduce a large proportion of mortalities related to hypertension [35]. 
According to our results, a clear distinction between groups was evident, particularly with respect to dietary patterns, physical activity, and hypertension control. Class I was distinguished from class II and class III as being the low-risk lifestyle with optimal BP control. Respondents who belong to class I tend to control their BP by medications and optimum diets and avoid smoking. Therefore, the probability of reaching recommended BP control was low in both classes II and III. The dietary indicators showed similar probabilities in classes I and II for having 4-5 DASH diet elements. Overall, regardless of latent-class analysis, the probability of reaching the recommended DASH diet intake was low across the whole sample. Södergren et al. [17] identified two classes of lifestyle when they used latent-class lifestyle modeling among older adults. They concluded that fruit intake was a good indicator distinguishing the "healthier" class, whereas consumption of vegetables and fast food (by women) could not clearly distinguish older adults in the other two classes. This is consistent with our data, showing an overall low consumption of vegetables and fruits compared with the recommended level among older adults. Similar results were obtained by Sodergren et al. [36]. DASH diet is the most effective diet for hypertension control and emphasizes fruits, vegetables, whole grains, low-fat dairy products, and products reduced in fat and cholesterol, with a low intake of red meat [37, 38].

Though less than one-fifth of the patients belonged to class I, they had relatively more probability of engaging in healthy behaviors related to hypertension control. For example, they have kept their blood pressure under control, adhered more to a DASH-style diet, and did not smoke. However, the vast majority of the participants had a lower probability of achieving the recommended level of physical activity. In particular, all of the groups shared similarly high probabilities of inadequate physical activity. Physical activity is commonly recommended as an important lifestyle modification that may aid in hypertension prevention $[39,40]$. Studies have shown that physical activity is a main predictor of progression from prehypertension to hypertension [41]. Whelton et al. found that exercise produces substantial improvements in systolic and diastolic blood pressure among older adults [42]. They also suggested that body composition improvements from physical activity are associated with BP reductions and improve cardiovascular health in older adults. A recent meta-analysis of 27 randomized trials documented a 4-mmHg reduction in systolic BP among older and middle-aged adults from an aerobic exercise intervention. Indeed, our findings are consistent with the physical activity guidelines that exercise of 30 min or more per day might reduce or control hypertension [36, 42].

It seems that clustering and identifying co-occurrence risk behaviors of an at-risk population may help prevent and lead to co-change, which is one of the most effective approaches in preventing high-risk behaviors [21].

It can be expected that older adult patients encounter multiple challenges and barriers to performing exercise and physical activity. In a study by Moschny et al., poor health emerged as the most important barrier to sufficient physical activity, and low perceived physical abilities were strongly associated with lower physical activity among older adults [43].

The majority of the participants in our study were illiterate, and a higher proportion of respondents did not adhere to the pattern of healthy lifestyles and physical activities. The results suggest that having a higher education level decreases the risk of membership in classes II and III. Consistent with our results, Baker et al. found that higher education was related to belonging to the healthiest class (2011) [44]. It can be concluded that lower education is associated with an unhealthy lifestyle pattern. Also, a 1 year increase in age increases the risk of membership from latent class I to class II and class III. Similarly, being married decreases the risk of membership in classes II and III seven times compared to divorced or widowed patients. Studies about healthy behavior by marital status has consistently identified that single individuals generally report poor health and have a higher mortality risk than their married counterparts [45].

To our knowledge, no research has investigated lifestyle pattern among hypertensive patients. However, one limitation of our study is that smoking as a criterion for clustering might not be a good indicator for predicting behavioral patterns in patients. Also, alcohol consuming among Iranian population is not possible to measure because people will not reply in a reliable and trustworthy way. Furthermore, it might be interesting for future studies to include other factors related to hypertension, like alcohol use.

\section{Conclusions}

Because behaviors often occur simultaneously within an individual, a latent-class approach might help cluster co-occurrence risk behaviors and focus on interventions targeting the several healthy behaviors among high-risk patients. The LCA assists investigators in identifying simple, latent-class patterns within complicated observed categorical indicators. Our study considers the subgrouping of an older adult patient sample into three classes. Results show a considerable percentage of patients in particular have uncontrolled hypertension. In addition, we found that marital status is more likely to 
be a preventive factor for unhealthy behavior. These analyses provide important insights into how we might target lifestyle-promoting strategies among older adult hypertensive patients. However, more research is needed to understand the modifiable determinants of these behavioral patterns so proper services can perform.

\author{
Abbreviations \\ BMI: Body mass index; DASH: Dietary approaches to stop hypertension; \\ FFQ: Food frequency questionnaire; IPAQ: International physical activity \\ questionnaire; LCA: Latent class analysis; MET: Metabolic equivalent; \\ PA: Physical activity
}

\section{Acknowledgments}

This manuscript originated from a MSc. thesis (IR.TBZMED.REC.1395.13) by JG, Department of Health Education and Promotion, faculty of Health, Tabriz, Iran. We are grateful to Tabriz University of Medical Sciences for providing facilities for the study. We wish to thank Urmia University of Medical Sciences for its support for the project. This study was not funded by special institutes.

\section{Funding}

There is no funding resource.

\section{Availability of data and materials}

The data collection tools and datasets generated and/or analyzed during the current study are available from the corresponding author on reasonable request.

\section{Authors' contributions}

JG was the main investigator, collected the data, and wrote the first draft. LJ was the study's supervisor and contributed to all aspects of the study and provided the final manuscript. AMA conducted the analysis, and MAF provided DASH diet categorization. JA have helped and consulted us in data gathering process. KP contributed substantially to the data interpretation and critically revised the final article for important intellectual content. All authors read and approved the paper.

\section{Ethics approval and consent to participate}

The study was approved by the Ethics Committee of Tabriz University of Medical Sciences (IR.TBZMED.REC.1395.13). All participants gave written informed consent. The data and material is available.

\section{Consent for publication}

Not applicable.

\section{Competing interests}

The authors declare no conflicts of interest.

\section{Publisher's Note}

Springer Nature remains neutral with regard to jurisdictional claims in published maps and institutional affiliations.

\section{Author details}

'Health Education and Health Promotion Department, School of Public Health, Tabriz University of Medical Sciences, Tabriz, Iran. ${ }^{2}$ Epidemiology and Biostatistics Department, School of Public Health, Tabriz University of Medical Sciences, Tabriz, Iran. ${ }^{3}$ Tabriz Health Services Management Research Center, Tabriz University of Medical Sciences, Tabriz, Iran. ${ }^{4}$ Drug Applied Research Center, Nutrition Research Center, Department of Community Nutrition, Tabriz University of Medical Sciences, Tabriz, Iran. ${ }^{5}$ Department of Public Health, Health and Paramedical Faculty, Urmia University of Medical Sciences, Nazlou Campus, Urmia, Iran. ${ }^{6}$ Department of Communication Sciences, Faculty of Political and Social Sciences, imec-mict-Ghent University, Ghent, Belgium.

Received: 5 December 2017 Accepted: 2 November 2018 Published online: 12 November 2018

\section{References}

1. Chobanian AV, Bakris GL, Black HR, Cushman WC, Green LA, Izzo JL Jr, Jones DW, Materson BJ, Oparil S, Wright JT Jr. The seventh report of the joint national committee on prevention, detection, evaluation, and treatment of high blood pressure: the JNC 7 report. Jama. 2003;289:2560-71.

2. Oparil S, Carter BL, Cushman WC, Dennison-Himmelfarb C, Handler J, Lackland DT, LeFevre ML, MacKenzie TD, Ogedegbe O, Smith SC. 2014 Evidence-Based Guideline for the Management of High Blood Pressure in Adults. 2014;311(5):507-20.

3. Danaei G, Finucane MM, Lin JK, Singh GM, Paciorek CJ, Cowan MJ, Farzadfar F, Stevens GA, Lim SS, Riley LM. National, regional, and global trends in systolic blood pressure since 1980: systematic analysis of health examination surveys and epidemiological studies with 786 country-years and 54 million participants. Lancet. 2011;377:568-77.

4. Chockalingam A, Campbell NR, Fodor JG. Worldwide epidemic of hypertension. Can J Cardiol. 2006;22:553-5.

5. Malekzadeh MM, Etemadi A, Kamangar F, Khademi H, Golozar A, Islami F, Pourshams A, Poustchi H, Navabakhsh B, Naemi M. Prevalence, awareness and risk factors of hypertension in a large cohort of Iranian adult population. J Hypertens. 2013;31:1364.

6. Weitzman D, Goldbourt U. The significance of various blood pressure indices for long-term stroke, coronary heart disease, and all-cause mortality in men. Isr Ischemic Heart Dis Stud. 2006;37:358-63.

7. Stocks T, Van Hemelrijck M, Manjer J, Bjørge T, Ulmer H, Hallmans G, Lindkvist B, Selmer R, Nagel G, Tretli S, et al. Blood pressure and risk of Cancer incidence and mortality in the metabolic syndrome and Cancer project. Hypertension. 2012;59:802-10.

8. Deaton C, Froelicher ES, Wu LH, Ho C, Shishani K, Jaarsma T. The global burden of cardiovascular disease. Eur J Cardiovasc Nurs. 2011; 1(10):S5-13.

9. Rezazadehkermani M. Epidemiology and heterogeneity of hypertension in Iran: a systematic review. Arch Iran Med. 2008;11:444-52.

10. Franklin SS, Gustin W, Wong ND, Larson MG, Weber MA, Kannel WB, Levy D. Hemodynamic patterns of age-related changes in blood pressure. Circulation. 1997:96:308-15.

11. Franklin SS, Larson MG, Khan SA, Wong ND, Leip EP, Kannel WB, Levy D. Does the relation of blood pressure to coronary heart disease risk change with aging? Circulation. 2001;103:1245-9.

12. Chobanian AV, Bakris GL, Black HR, Cushman WC, Green LA, Izzo JL Jr, et al. The seventh report of the joint national committee on prevention, detection, evaluation, and treatment of high blood pressure: the JNC 7 report. JAMA. 2003;289(19):2560-71.

13. Ford ES, Zhao G, Tsai J, Li C. Low-risk lifestyle behaviors and all-cause mortality: findings from the National Health and nutrition examination survey III mortality study. Am J Public Health. 2011;101:1922-9.

14. Poortinga $W$. The prevalence and clustering of four major lifestyle risk factors in an English adult population. Prev Med. 2007;44:124-8.

15. Kvaavik E, Batty GD, Ursin G, Huxley R, Gale CR. Influence of individual and combined health behaviors on total and cause-specific mortality in men and women: the United Kingdom health and lifestyle survey. Arch Intern Med. 2010;170:711-8.

16. Mancia G, Fagard R, Narkiewicz K, Redon J, Zanchetti A, Böhm M, Christiaens T, Cifkova R, De Backer G, Dominiczak A. 2013 ESH/ESC guidelines for the management of arterial hypertension: the task force for the Management of Arterial Hypertension of the European Society of Hypertension (ESH) and of the European Society of Cardiology (ESC). Blood Press. 2013;22:193-278.

17. Laska MN, Pasch KE, Lust K, Story M, Ehlinger E. Latent class analysis of lifestyle characteristics and health risk behaviors among college youth. Prev Sci. 2009;10:376-86.

18. Lanza ST, Flaherty BP, Collins LM. Latent class and latent transition analysis. In: Handbook of psychology; 2003.

19. Funderburk JS, Maisto SA, Sugarman DE, Wade M. The covariation of multiple risk factors in primary care: a latent class analysis. J Behav Med. 2008;31:525-35.

20. Huh J, Riggs NR, Spruijt-Metz D, Chou C-P, Huang Z, Pentz M. Identifying patterns of eating and physical activity in children: a latent class analysis of obesity risk. Obesity (Silver Spring, Md). 2011;19:652-8.

21. Scotto Rosato N, Baer JC. Latent class analysis: a method for capturing heterogeneity. Soc Work Res. 2012;36:61-9.

22. Esfahani FH, Asghari G, Mirmiran P, Azizi F. Reproducibility and relative validity of food group intake in a food frequency questionnaire developed for the Tehran lipid and glucose study. J Epidemiol. 2010;20: $150-8$. 
23. McGuire S. US Department of Agriculture and US Department of Health and Human Services, dietary guidelines for Americans, 2010. Washington, DC: US government printing office, January 2011. Adv Nutr. 2011;2:293-4.

24. Vasheghani-Farahani A, Tahmasbi M, Asheri H, Ashraf H, Nedjat S, Kordi R. The Persian, last 7-day, long form of the international physical activity questionnaire: translation and validation study. Asian J Sports Med. 2011;2:106.

25. Haskell WL, Lee I-M, Pate RR, Powell KE, Blair SN, Franklin BA, Macera CA, Heath GW, Thompson PD, Bauman A. Physical activity and public health: updated recommendation for adults from the American College of Sports Medicine and the American Heart Association. Med Sci Sports Exerc. 2007; 39:1423-34.

26. Ismail LC, Knight H, Ohuma E, Hoch L, Chumlea W. Anthropometric standardisation and quality control protocols for the construction of new, international, fetal and newborn growth standards: the INTERGROWTH21stProject. BJOG. 2013;120(0 2):48-v.

27. de Onis M, Onyango AW, Van den Broeck J, Chumlea CW, Martorell R. Measurement and standardization protocols for anthropometry used in the construction of a new international growth reference. Food Nutr Bull. 2004; 25(1_suppl1):S27-36.

28. Alberti KGM, Zimmet $P$, Shaw J. The metabolic syndrome-a new worldwide definition. Lancet. 2005:366(9491):1059.

29. Hagenaars J, McCutcheon A. Applied latent class analysis. New York: Cambridge University Press; 2002

30. Nylund KL, Asparouhov T, Muthén BO. Deciding on the number of classes in latent class analysis and growth mixture modeling: a Monte Carlo simulation study. Struct Equ Model. 2007;14(4):535-69.

31. Muthén BO. Latent variable mixture modeling, in New Developments and Techniques in Structural Equation Modeling. Edited by Marcoulides GA, Schumacker RE. Mahwah, NJ, Lawrence Erlbaum Associates. 2001. p 1-33.

32. Ogasawara H. Bias correction of the Akaike information criterion in factor analysis. J Multivar Anal. 2016;149:144-59.

33. Go AS, Bauman MA, Coleman King SM, Fonarow GC, Lawrence W, Williams KA, Sanchez E. An effective approach to high blood pressure control. A Science Advisory From the American Heart Association, the American College of Cardiology, and the Centers for Disease Control and Prevention. Hypertension. 2014;63(4):878-85.

34. Lloyd-Jones DM, Hong Y, Labarthe D, Mozaffarian D, Appel L, Van Horn L, Greenlund K, Daniels S, Nichol G, Tomaselli GF. Defining and setting national goals for cardiovascular health promotion and disease reduction. Circulation. 2010;121:586-613.

35. Ford ES, Ajani UA, Croft JB, Critchley JA, Labarthe DR, Kottke TE, Giles WH, Capewell S. Explaining the decrease in US deaths from coronary disease, 1980-2000. N Engl J Med. 2007;356:2388-98.

36. Sodergren M, Wang WC, Salmon J, Ball K, Crawford D, McNaughton SA. Predicting healthy lifestyle patterns among retirement age older adults in the WELL study: a latent class analysis of sex differences. Maturitas. 2014;77:41-6.

37. Appel LJ. Lifestyle modification as a means to prevent and treat high blood pressure. J Am Soc Nephrol. 2003;14(suppl 2):S99-S102.

38. Juraschek SP, Gelber AC, Choi HK, Appel LJ, Miller ER. Effects of the dietary approaches to stop hypertension (DASH) diet and sodium intake on serum uric acid. Arthritis Rheumatol. 2016;68:3002-9.

39. Cornelissen VA, Smart NA. Exercise training for blood pressure: a systematic review and meta-analysis. J Am Heart Assoc. 2013;2:e004473.

40. Guo X, Zou L, Zhang X, Li J, Zheng L, Sun Z, Hu J, Wong ND, Sun Y. Prehypertension: a meta-analysis of the epidemiology, risk factors, and Predictors of Progression. Tex Heart Inst J. 2011;38:643-52.

41. Stewart KJ, Bacher AC, Turner KL, Fleg JL, Hees PS, Shapiro EP, Tayback M, Ouyang P. Effect of exercise on blood pressure in older persons: a randomized controlled trial. Arch Intern Med. 2005;165:756-62.

42. Whelton SP, Chin A, Xin X, He J. Effect of aerobic exercise on blood pressurea meta-analysis of randomized, controlled trials. Ann Intern Med. 2002;136:493-503.

43. Moschny A, Platen P, Klaaßen-Mielke R, Trampisch U, Hinrichs T. Barriers to physical activity in older adults in Germany: a cross-sectional study. Int J Behav Nutr Phys Act. 2011;8:121.

44. Baker DP, Leon J, Smith Greenaway EG, Collins J, Movit M. The education effect on population health: a reassessment. Popul Dev Rev. 2011;37:307-32.

45. Robards J, Evandrou M, Falkingham J, Vlachantoni A. Marital status, health and mortality. Maturitas. 2012;73:295-9.

\section{Ready to submit your research? Choose BMC and benefit from:}

- fast, convenient online submission

- thorough peer review by experienced researchers in your field

- rapid publication on acceptance

- support for research data, including large and complex data types

- gold Open Access which fosters wider collaboration and increased citations

- maximum visibility for your research: over $100 \mathrm{M}$ website views per year

At $\mathrm{BMC}$, research is always in progress.

Learn more biomedcentral.com/submissions 